\title{
Survey of awareness about the risk factors of low back pain among operating room personnel of Shiraz hospitals: A cross-sectional study
}

\author{
Reza Tavakkol $^{\mathrm{a}}$, Jamshid Eslami ${ }^{\mathrm{b}, * *}$, Azadeh Amiri $^{\mathrm{a}}$, Ladan Zarshenas ${ }^{\mathrm{c}}$ \\ ${ }^{a}$ Operating Room Group, School of Nursing and Midwifery, Shiraz University of Medical Science, Shiraz, Iran \\ ${ }^{\mathrm{b}}$ Department of Nursing, School of Nursing and Midwifery, Shiraz University of Medical Sciences, Shiraz, Iran \\ ${ }^{\mathrm{c}}$ Community-Based Psychiatric Care Research Center, School of Nursing and Midwifery, Shiraz University of Medical Sciences, Shiraz, Iran
}

\section{A R T I C L E I N F O}

\section{Keywords:}

Low back pain

Operating room

Musculoskeletal disorders

\begin{abstract}
A B S T R A C T
Background: and Purpose: Low back pain is one of the most common musculoskeletal disorders and one of the costly problems in the health system. The purpose of this study was to evaluate the prevalence of low back pain and its relationship with the awareness of operating room personnel about the risk factors of low back pain. Materials and methods: This cross-sectional study was performed on 385 operating room personnel of the hospitals affiliated to Shiraz University of Medical Sciences. The data were collected through a researcher-made questionnaire. The questionnaire consisted of two parts, including the assessment of low back pain prevalence and dimensions (11 items) and the evaluation of participants' awareness regarding low back pain risk factors (17 items).

Results: The results showed that the prevalence of low back pain was 74\% among operating room personnel. Also, the mean and standard deviation of the participant's awareness of low back pain factors was 24.88 \pm 4.18 . Also, there was no significant relationship between the prevalence of low back pain and awareness of the personnel about the risk factors of low back pain ( $\left.\mathrm{p}^{>} 0.05\right)$.

Conclusion: Due to importance of operating room in hospital, operating room managers and the authorities should promote operating room programs focusing on reducing musculoskeletal disorders and try to increase the awareness of operating room personnel about the risk factors by conducting classes and training courses.
\end{abstract}

\section{Introduction}

Musculoskeletal disorders are one of the most common health problems, accounting for the second leading cause of physical disability worldwide. ${ }^{1}$ Musculoskeletal disorders are responsible for the significant burden on health care costs, leading to harmful effects on the personnel's health, quality of life, job satisfaction, and working days wasted. $^{2}$

Low back pain (LBP) is the most common and costly problem among work-related musculoskeletal disorders in the healthcare system that defined as pain or discomfort in the space between the 12th rib and the inferior gluteal folds. ${ }^{3-6}$ Pathologically, such a disorder ranks eighth among all physical injuries, accounting for the most common cause of activity restriction among individuals younger than 45 years old ${ }^{1,7}$ and the second most common diagnosis in the United States. ${ }^{8}$ The prevalence of LBP is reported to be $15-45 \%$ among the general population worldwide. ${ }^{9,10}$ Of note, the prevalence of LBP is increasing among healthcare workers, nurses, and operating room personnel with a prevalence of $40-50 \%$ per year. ${ }^{9}$ According to high-risk operating room activities, LBP is a common health problem among these personnel, so that the personnel in this place is more affected by musculoskeletal pain with the rate of 58-90\% after one year of clinical work. ${ }^{9,11}$ Importantly, LBP is recognized as the most important reason for quitting the job in operating room personnel ${ }^{12}$

Factors leading to LBP include carrying things, standing for a long time, fixed body posture, holding equipment (such as retractors during surgery), manual material handling (such as pulling or pushing or lifting tools, patients, and heavy equipment), unpleasant physical condition, and movement limitations (during surgery and working at night shifts). ${ }^{13}$ Such risk factors lead to a higher prevalence of LBP in healthcare workers, specifically among the operating room personnel. ${ }^{14}$ Careful observation of the principles of ergonomics in the workplace, identification of risk factors, regular physical checkup, exercise, and regular physical activity have been identified as effective contributors

\footnotetext{
* Corresponding author.

E-mail addresses: Tavakkolreza.73@gmail.com (R. Tavakkol), jam_eslami@yahoo.com (J. Eslami), amiriea@sums.ac.ir (A. Amiri), zarshenas@sums.ac.ir (L. Zarshenas).
} 
to the reduction of LBP. ${ }^{15}$ Most importantly, the hospital environment, especially the operating room, is filled with a variety of occupational hazards and injuries that pose many risks for the personnel. Knowledge is expected to play an important role in decreasing such risks. ${ }^{16,17}$

Awareness, defined as the repetition of responses previously learned, practiced, and obtained, is recognized as a tool capable of modifying behavior or, at least, making more appropriate behavior to bring oneself to the desired level of health. Increasing awareness of the risk factors of LBP can decrease the high prevalence of this disorder and prevent its subsequent complications. According to the role of awareness of healthcare personnel about the risk factors in occupational injuries and lack of similar research in Iran, the aim of this study was to survey the awareness about the risk factors of LBP among the operating room personnel of Shiraz hospitals.

\section{Materials and Methods}

\subsection{Study design}

The present descriptive cross-sectional study was conducted between May to June 2019 to on the operating room personnel of 6 hospitals affiliated to Shiraz University of Medical Sciences, including Faghihi, Namazee, Khalili, Chamran, Rajaey and Amiralmomenin hospitals.

\subsection{Sample size and recruitment of study subjects}

According to the similar study, ${ }^{18} 385$ individuals were selected in this study, based on the average prevalence (50\%) of LBP in operating room personnel. The sample size chosen for this study was calculated with an accuracy of 0.05 and the prevalence and confidence estimates of $95 \%$.

\subsection{Data collection}

In the present study, we first determined the entire number of operating room personnel in each hospital and subsequently the personnel were chosen according to stratified random sampling. For this purpose, we referred to hospitals in various shifts following permission from the Ethics Committee, and the sampling was performed according to the criteria mentioned in different shifts after obtaining informed and written consent from the personnel. The questionnaires were distributed among the personnel and then collected at the end of the office time on the same day.

\subsection{Inclusion and exclusion criteria}

Participants were eligible for the study if they met the following inclusion criteria:

1 A minimum of 2-year experience in work

2 No musculoskeletal disease

3 Willingness to participate in the study

Participants were excluded from the study if they met one of the following exclusion criteria:

1 Suffering from osteoporosis or corticosteroid

2 Discontent to participate in the study

\subsection{Research instruments}

A research-made questionnaire was used to evaluate the factors related to LBP and also the awareness of LBP risk factors in personnel. The validity and reliability of the questionnaire had already been examined. During the psychometric part of this instrument, qualitative and quantitative methods were used to determine the face validity, content and construct validity evaluation. Face validity of the qualitative was checked by interviews with 20 professors and experts in this field, resulting in a modification of 3 items and the addition of 2 items. During the quantitative face validity phase, which assessed the importance of each item by using the item impact formula, all tool items received the least impact score. This was done by filling out the initial questionnaire by 20 operating room personnel. The content validity of the qualitative section was determined by the experts' correction; 3 items were corrected and 1 item merged in the other items. Quantitative evaluation of the content validity was done by using two indices of content validity ratio and content validity index, which were 14 and 10 people from professors and experts in this field, respectively. In this phase, 2 items failed to achieve the required score and was eliminated. The construct validity assessment was done through the convergent and divergent validity, respectively, using chronic Pain Questionnaire and General Health Questionnaire distributed among 30 operating room personnel. The correlation of the mentioned instruments was investigated with the research instrument. The relationship between the research instrument with the chronic pain questionnaire, as a convergent tool and the General Health Questionnaire, as a divergent instrument, was 0.702 and -0.375 , respectively, which was statistically significant $\left(\mathrm{P}^{<} 0.05\right)$. Reliability and internal consistency of the instrument, determined by test-retest and Cronbach's alpha coefficient, were found to be 0.78 and 0.608 , respectively.

The questionnaire consisted of three sections: "Demographic information, prevalence and dimensions of LBP, assessment of awareness of LBP risk factors". In this questionnaire, the prevalence and dimensions of LBP were assessed by using 11 multiple choice questions, and the awareness section was evaluated by using 17 items with Likert spectrum "Yes, No, or I don't know". The score of LBP was found to be in the range of $0-34$. The subjects were divided into three groups, including low awareness (0-10), moderate ${ }^{11-15}$ and high scores (16-20) based on the score number $20 . .^{18}$

\subsection{Statistical analysis}

After collecting the questionnaires, the data were entered into SPSS version 20 and then analyzed. Demographic data of the population were calculated by descriptive statistics, frequency distribution, mean, and standard deviation. Chi-square, $t$-test and correlation coefficient were used to investigate the relationship between LBP prevalence and awareness of LBP risk factors with demographic variables.

\subsection{Ethics statement}

The present study was conducted in accordance with the recommendations of ethical guidelines, IR.SUMS.REC.1398.263. The protocols carried out in this investigation were approved by Shiraz University of Medical Sciences.

\section{Results}

Three hundred eighty-five operating room personnel working in 6 hospitals affiliated to Shiraz University of Medical Sciences were studied in this study. Table 1 indicates the frequency distribution of the demographic characteristics of the population under study. 240 $(62.3 \%)$ out of 385 participants were women in the study. The mean and standard deviation of age were $7.96 \pm 33.25$. Most of the participants were bachelor (85.7\%), had less than 10 years of working experience $(60.3 \%)$, and had experienced a combination of standing, sitting and moving (30.9\%) during the work. In this study, public media and social networks were identified as the largest source of information on LBP (35.3\%).

The prevalence of LBP in different hospitals is shown in Table 2. 285 (74\%) participants had LBP. Among people with LBP, women had the 
Table 1

Determining demographic characteristics of the operating room personnel.

\begin{tabular}{|c|c|c|}
\hline Variable & & Frequency (\%) \\
\hline \multirow[t]{2}{*}{ Gender } & Female & 145 (37.7) \\
\hline & Male & $240(62.3)$ \\
\hline \multirow[t]{4}{*}{ Age } & 20-29 years & $155(40.3)$ \\
\hline & 30-39 years & $150(39)$ \\
\hline & $40-50$ years & $58(15.1)$ \\
\hline & Above 50 years & $22(5.7)$ \\
\hline \multirow[t]{2}{*}{ Marital status } & Single & $162(42.6)$ \\
\hline & Married & $221(57.4)$ \\
\hline \multirow[t]{3}{*}{ Education level } & Associate degree & $45(11.7)$ \\
\hline & Bachelor degree & $330(85.7)$ \\
\hline & Master degree & $10(2.6)$ \\
\hline \multirow[t]{3}{*}{ Work experience } & Less than 10 years & $232(60.3)$ \\
\hline & $10-20$ years & $109(28.3)$ \\
\hline & More than 20 years & $44(11.4)$ \\
\hline \multirow[t]{4}{*}{ Shifts } & Morning & $60(15.6)$ \\
\hline & Evening & $33(8.6)$ \\
\hline & Night & $16(4.2)$ \\
\hline & Shift on the trip & $276(71.7)$ \\
\hline \multirow[t]{4}{*}{ Physical condition } & Standing & $208(54)$ \\
\hline & Sitting & $37(9.6)$ \\
\hline & Moving & $21(5.5)$ \\
\hline & $\begin{array}{l}\text { A combination of different physical } \\
\text { conditions }\end{array}$ & $119(30.9)$ \\
\hline \multirow[t]{6}{*}{ Source of information } & Public media and social networks & $136(35.3)$ \\
\hline & $\begin{array}{l}\text { Participation in scientific conferences } \\
\text { and forums }\end{array}$ & $3(0.8)$ \\
\hline & People around & $72(18.7)$ \\
\hline & Studding & $56(14.5)$ \\
\hline & Educated in university & $96(24.9)$ \\
\hline & Others & $22(5.7)$ \\
\hline
\end{tabular}

Table 2

Prevalence of LBP in the studied hospitals.

\begin{tabular}{|c|c|c|c|}
\hline Hospital name & $\begin{array}{l}\text { Number of } \\
\text { personnel }\end{array}$ & $\begin{array}{l}\text { Type of operating } \\
\text { room }\end{array}$ & $\begin{array}{l}\text { The prevalence of } \\
\text { low back pain } \\
\text { Frequency }(\%)\end{array}$ \\
\hline Faghihi & 83 & General & $62(74.6)$ \\
\hline Namazee & 94 & General & $62(65.9)$ \\
\hline Khalili & 49 & Eye and ENT & $37(75.5)$ \\
\hline Rajaey & 85 & $\begin{array}{l}\text { Orthopedics- } \\
\text { Nerves }\end{array}$ & $68(80)$ \\
\hline Chamran & 55 & $\begin{array}{l}\text { Orthopedics- } \\
\text { Nerves }\end{array}$ & $40(72.7)$ \\
\hline Amiralmomenin & 19 & Burn and plastic & $16(84.2)$ \\
\hline Total & 385 & 385 & $285(74)$ \\
\hline
\end{tabular}

highest rate of LBP (76.6\%), participants aged 30-39 years (40.3\%), married ones $(78.7 \%)$, those with more than 20 years of work experience $(81.3 \%)$, and people with standing posture $(78.3 \%)$. Most participants were in the general operating room (47.5\%), but the highest prevalence of LBP was observed in the burn and plastic operating room (84.2\%). Only $46(16.1 \%)$ out of $285(74.02 \%)$ patients with LBP had a history of absenteeism due to LBP (Table 2).

The prevalence of LBP exhibited a direct and significant relationship with the association degree and married people $(\mathrm{p}<0.05)$, and public media and social networks ( $\mathrm{p}<0.05)$; however, the relationship was in the reverse direction (Table 3 ).

The mean and standard deviation of the participants' awareness of LBP risk factors was $4.18 \pm 24.88$; in addition, the lowest and highest levels of recorded knowledge were 14 and 34, respectively. Among the participants, 189 (49.1\%), 185 (48.1\%), and only 11 (2.9\%) had good knowledge, moderate awareness, and low awareness regarding risk factors of LBP. In this study, the highest level of awareness was related to women, single people, people with bachelor's degree, and people with ages over 20 years with $49.5 \%, 50 \%, 50.9 \%$, and $52.2 \%$, respectively (Table 4).
Table 3

The relationship between low back pain and demographic characteristics of the operating room personnel.

\begin{tabular}{|c|c|c|c|}
\hline Variable & & $\begin{array}{l}\text { The prevalence of } \\
\text { low back pain } \\
\text { Frequency }(\%)\end{array}$ & $\begin{array}{l}\text { The } \\
\text { significance } \\
\text { level }\end{array}$ \\
\hline \multirow[t]{2}{*}{ Gender } & Male & $101(69.6)$ & 0.128 \\
\hline & Female & $184(76.6)$ & \\
\hline \multirow[t]{4}{*}{ Age } & 20-29 years & $108(37.8)$ & 0.413 \\
\hline & $30-39$ years & $115(40.3)$ & \\
\hline & $40-50$ years & $44(15.4)$ & \\
\hline & More than 50 years & $18(6.3)$ & \\
\hline \multirow[t]{2}{*}{ Marital status } & Single & $111(67.6)$ & 0.014 \\
\hline & Married & $174(78.7)$ & \\
\hline \multirow[t]{3}{*}{ Education level } & Associated degree & 35 (77.7) & 0.041 \\
\hline & Bachelor degree & $246(74.5)$ & \\
\hline & Master degree & $4(40)$ & \\
\hline \multirow[t]{3}{*}{ Work experience } & Less than 10 years & $165(71.1)$ & 0.231 \\
\hline & $10-20$ years & $84(77.06)$ & \\
\hline & More than 20 years & 35 (81.3) & \\
\hline \multirow[t]{4}{*}{ Shifts } & Morning & $46(76.6)$ & 0.496 \\
\hline & Evening & $22(66.6)$ & \\
\hline & Night & $10(62.5)$ & \\
\hline & Shift on the trip & $207(75)$ & \\
\hline \multirow[t]{4}{*}{ Physical condition } & Standing & $163(78.3)$ & 0.075 \\
\hline & Sitting & $22(59.4)$ & \\
\hline & Moving & $16(76.1)$ & \\
\hline & $\begin{array}{l}\text { A combination of } \\
\text { different physical } \\
\text { conditions }\end{array}$ & $84(70.5)$ & \\
\hline \multirow[t]{6}{*}{$\begin{array}{l}\text { Source of } \\
\text { information }\end{array}$} & $\begin{array}{l}\text { Public media and } \\
\text { social networks }\end{array}$ & $110(80.8)$ & 0.042 \\
\hline & $\begin{array}{l}\text { Participation in } \\
\text { scientific } \\
\text { conferences and } \\
\text { forums }\end{array}$ & $1(33.3)$ & \\
\hline & People around & $52(72.2)$ & \\
\hline & studding & $38(67.8)$ & \\
\hline & $\begin{array}{l}\text { Educated in } \\
\text { university }\end{array}$ & $72(75)$ & \\
\hline & Others & $12(54.5)$ & \\
\hline
\end{tabular}

Table 5 shows the level of awareness of the personnel in different hospitals. Personnel's awareness was not significantly correlated to demographic variables $\left(p^{>} 0.05\right)$. The most awareness about the risk factors of LBP was found in the staff working in the orthopedic and nerve operating room of Chamran Hospital (63.6\%).

The relationship between the prevalence of LBP and the awareness of LBP risk factors is shown in Table 6. Out of 74\% of LBP patients, $52.2 \%$ had a high awareness of LBP risk factors and, only $3.1 \%$ had low awareness. Out of $100(25.9 \%)$ people who did not experience LBP in this study, $98 \%$ had moderate and desirable awareness while only $2 \%$ had a low level of awareness. Moreover, no significant relationship was found between the personnel's awareness of risk factors and the prevalence of $L B P\left(p^{>0} 0.05\right)$.

\section{Discussion}

This study evaluated the prevalence and factors associated with LBP as well as assessed the awareness of LBP risk factors in the operating room personnel of 6 hospitals affiliated to Shiraz University of Medical Sciences. Results from this study showed moderate and desirable awareness among most participants. However, the prevalence of LBP was high in all hospitals.

LBP has been identified as one of the most important musculoskeletal disorders that can lead to absenteeism and even changing job in operating room personnel $(5,25)$. This indicates the inevitability of LBP due to difficult working conditions in the operating room. In the present study, similar to other studies, LBP was prevalent among operating room personnel, demonstrating that LBP is inevitable and occurs due to 
Table 4

The relationship between awareness of low back pain risk factors with demographic characteristics of operating room personnel.

\begin{tabular}{|c|c|c|c|c|c|}
\hline \multirow[t]{3}{*}{ Variable } & & \multicolumn{3}{|c|}{ Awareness of low back pain risk factors } & \multirow[t]{3}{*}{ Significance levels } \\
\hline & & Low & Moderate & High & \\
\hline & & Frequency (\%) & Frequency (\%) & Frequency (\%) & \\
\hline \multirow[t]{2}{*}{ Gender } & Male & $7(4.8)$ & $68(46.8)$ & $70(48.2)$ & 0.196 \\
\hline & Female & $4(1.6)$ & 117 (48.7) & $119(49.5)$ & \\
\hline \multirow[t]{2}{*}{ Marital status } & Single & $5(3.04)$ & 77 (46.9) & $82(50)$ & 0.925 \\
\hline & Married & $6(2.7)$ & $108(48.8)$ & $107(48.4)$ & \\
\hline \multirow[t]{3}{*}{ Education } & Associate degree & $1(2.2)$ & $28(62.2)$ & $16(35.5)$ & 0.349 \\
\hline & Bachelor degree & $10(3.03)$ & $152(46.06)$ & $168(50.9)$ & \\
\hline & Master degree & $0(0)$ & $5(50)$ & $5(50)$ & \\
\hline \multirow[t]{3}{*}{ Work experience } & Less than 10 years & $6(2.5)$ & 109 (46.9) & $117(50.4)$ & 0.336 \\
\hline & $10-20$ years & $2(1.8)$ & $58(53.2)$ & $49(44.9)$ & \\
\hline & More than 20 years & $3(6.8)$ & $18(40.9)$ & $23(52.2)$ & \\
\hline
\end{tabular}

Table 5

The awareness of operating room personnel about the risk factors of LBP in hospitals studied.

\begin{tabular}{llll}
\hline Hospital name & \multicolumn{2}{l}{ Awareness } \\
\cline { 2 - 4 } & Low & Moderate & High \\
\cline { 2 - 4 } & Frequency (\%) & Frequency (\%) & Frequency (\%) \\
\hline Faghihi & $1(1.2)$ & $40(48.1)$ & $42(50.6)$ \\
Namazee & $6(6.3)$ & $43(45.7)$ & $45(47.8)$ \\
Khalili & $4(8.1)$ & $31(63.2)$ & $14(28.5)$ \\
Rajaey & $0(0)$ & $44(51.7)$ & $41(48.2)$ \\
Chamran & $0(0)$ & $20(36.3)$ & $35(63.6)$ \\
Amiralmomenin & $0(0)$ & $7(36.8)$ & $12(63.1)$ \\
Total & $11(2.8)$ & $185(48.05)$ & $189(49.09)$ \\
\hline
\end{tabular}

the operating room conditions. In addition, we found that a considerable amount of (16.1\%) of people with LBP had a history of absenteeism with or without medical treatment. In a study carried out in Xinjiang in 2017, Ping Yan et al. investigated the prevalence of workrelated musculoskeletal disorders on 6674 nurses with a mean age of $7.18 \pm 31.83$, demonstrating the highest prevalence rate of LBP (62.71\%). In addition, our results showed that LBP was the most reason for the requested leave time of nurses $(5.50 \%)$ among the musculoskeletal disorders (27). The prevalence of LBP in the study carried out by Ping Yan et al. was high (74.02\%), which was consistent with our findings, indicating the high extent of this disorder among health care workers.

In the present study, $16.1 \%$ of the people with LBP had a history of absenteeism with or without medical treatment, which was higher than that of the study carried out by Ping Yan et al. This may be due to the lack of diagnosis of sick leave and the absence without physician's prescription. Our results showed that the prevalence of LBP was high in different hospitals. In addition, various prevalence levels found in different hospitals were due to the type of operating rooms of each hospital. The orthopedic and nerve operating room often had a higher rate of LBP due to the higher operating pressure. In a study conducted in Yazd in 2012, Barkhordari et al. investigated the prevalence of LBP among 351 nurses, demonstrating the highest prevalence of LBP in the nurses working in orthopedic surgery and operating room, respectively (28). The results of that study were in line with those from the present study. This high incidence may be due to the increased work pressure on the personnel in this type of operating room.

Another aim of our study was to measure the awareness of operating room personnel about the risk factors of LBP. In this study, more than $97 \%$ of the participants had moderate to high levels of awareness while only a limited number had low awareness of the risk factors for LBP. In addition, public media and social networks played the highest role among the sources of information acquisition. A study, conducted by Choubineh et al. in 2012, evaluated the level of awareness of LBP risk factors, in which 118 nurses were evaluated in 8 hospitals of Shiraz. They showed that the awareness of nurses about LBP was not desirable and needed to be improved. In addition, they found university Education levelas the most important source of information for nurses about LBP. ${ }^{3}$

According to the above, the time difference between these two studies as well as the ever-expanding cyberspace and its access to personal lives, the public media and social networks probably play a more prominent role in people's awareness of different areas. On the other hand, the awareness level of LBP in the present study was higher than that carried out by of Chubinha et al. This could be due to different research environment and specificity of the study population, different measuring tools, as well as ease of access to relevant resources in the area of health through the development of Internet and cyberspace. The peak of LBP is in the third decade of life. ${ }^{8}$ The mean age of the study participants was 32 years, indicating that many participants were in their third decade of life. Meanwhile, the mean of LBP was higher in subjects of this age group than the average of LBP. Another study conducted by Muscato et al. in 2010, examined musculoskeletal injuries in 185 operating room personnel in Rome, Italy, with a mean age of $36.08 \pm 7.08$. That study found LBP as the most important musculoskeletal disorder (29). Accordingly, the mean age of the subjects in the study performed by Muscatato and the present study was close and above 30 years; this factor itself could have a significant role in the high prevalence of LBP in these studies.

Table 6

The relationship between awareness of LBP risk factors and prevalence of LBP in operating room personnel.

\begin{tabular}{|c|c|c|c|c|c|}
\hline \multirow[t]{3}{*}{ Variable } & & \multicolumn{3}{|c|}{ Awareness of low back pain risk factors } & \multirow[t]{3}{*}{ The significance level } \\
\hline & & Low & Moderate & High & \\
\hline & & Frequency (\%) & Frequency (\%) & Frequency (\%) & \\
\hline \multirow[t]{2}{*}{ Low back pain } & Have & $9(3.1)$ & $127(44.5)$ & $149(52.2)$ & 0.067 \\
\hline & Haven't & $2^{2}$ & $58(58)$ & $40(40)$ & \\
\hline
\end{tabular}




\section{Conclusion}

A high prevalence of LBP and relatively high awareness rates of LBP risk factors in operating room personnel was found in this study. There was no significant relationship between LBP and awareness of operating room personnel about LBP risk factors. Although the level of awareness was desirable, the prevalence of LBP was also high, which could be due to the gap between their awareness and practice of LBP risk factors. However, there is a need for more studies to assess the awareness of operating room personnel about the risk factors and its relation to the prevalence of LBP and the causality of the relationship between them. In addition and importantly, the managers and authorities should promote operating room programs focusing on decreasing musculoskeletal disorders and try to increase the awareness of operating room personnel about the risk factors by holding training programs.

\section{Limitation}

The limitations of this study include no involvement of students and operating room personnel working on private hospitals. Additionally, assessment of other risk factors, including mental status and occupational stress, could yield better results among operating room personnel. Most importantly, it is recommended future studies evaluate students and private hospitals.

\section{Declaration of competing interest}

This study was funded by Shiraz University of Medical Sciences. Also, this study was conducted in accordance with the recommendations of ethical guidelines, IR.SUMS.REC.1398.263. The protocols carried out in this investigation were approved by Shiraz University of Medical Sciences.

\section{Acknowledgments}

The authors would like to thank all the personnel involved in this study, Shiraz University of Medical Sciences, Shiraz, Iran, as well as Center for Development of Clinical Research of Nemazee Hospital. We also thank Dr. Nasrin Shokrpour for editorial assistance. The present article was extracted from the Master's thesis under Project No. 97-01-
08-18404 and Ethics Code of IR.SUMS.REC.1398.263.

\section{References}

1. Vos T, Flaxman AD, Naghavi M, et al. Years lived with disability (YLDs) for 1160 sequelae of 289 diseases and injuries 1990-2010: a systematic analysis for the Global Burden of Disease Study 2010. The lancet. 2012;380(9859):2163-2196.

2. Richardson A, McNoe B, Derrett S, Harcombe H. Interventions to prevent and reduce the impact of musculoskeletal injuries among nurses: a systematic review. Int $J$ Nurs Stud. 2018;82:58-67.

3. Cunningham C, Flynn T, Blake C. Low back pain and occupation among Irish health service workers. Occup Med. 2006;56(7):447-454.

4. Choobineh A, Baghertaghipour M, Tabatabaie H, Kammalinia M. Study of nurses' knowledge on low back pain risk factors in Hospitals of Shiraz University of Medical Sciences. Journal of Health and Safety at Work. 2012;2(1):55-62.

5. Woolf AD, Erwin J, March L. The need to address the burden of musculoskeletal conditions. Best Pract Res Clin Rheumatol. 2012;26(2):183-224.

6. Bhandary AK, Chimes GP, Malanga GA. Investigational pharmacology for low back pain. J Pain Res. 2010;3:169.

7. Cust G. The prevalence of low back pain in nurses. Int Nurs Rev. 1972;19:169-178.

8. Starkweather AR, Ramesh D, Lyon DE, et al. Acute low back pain: differential somatosensory function and gene expression compared to healthy no-pain controls. Clin $J$ Pain. 2016;32(11):933.

9. Bin Homaid M, Abdelmoety D, Alshareef W, et al. Prevalence and risk factors of low back pain among operation room staff at a Tertiary Care Center, Makkah, Saudi Arabia: a cross-sectional study. Ann Occup Environ Med. 2016;28:1.

10. Rostami K, Sharif F, Zarshenas L, Ebadi A, Farbood A. Design and psychometrics of measurement tool of health needs in patients with chronic back ache. Revista Latinoamericana de Hipertension. 2018;13(3):277.

11. Nützi M, Koch P, Baur H, Elfering A. Work-Family conflict, task interruptions, and influence at work predict musculoskeletal pain in operating room nurses. Safety and health at work. 2015;6(4):329-337.

12. Phillips N. Berry \& Kohn's Operating Room Technique. Elsevier Health Sciences; 2016.

13. Choobineh A, Movahed M, Tabatabaie SH, Kumashiro M. Perceived demands and musculoskeletal disorders in operating room nurses of Shiraz city hospitals. Ind Health. 2010;48(1):74-84.

14. Attar SM. Frequency and risk factors of musculoskeletal pain in nurses at a tertiary centre in Jeddah, Saudi Arabia: a cross sectional study. BMC Res Notes. 2014:7(1):61.

15. Samaei SE, Mostafaee M, Jafarpoor H, Hosseinabadi MB. Effects of patient-handling and individual factors on the prevalence of low back pain among nursing personnel. Work. 2017;56(4):551-561.

16. Asadpour M, Ghofranipour F, EftekharArdebili H, Niknami S, Hajizadeh E. Compliance with standard precautions among nursing care workers. Journal of Rafsanjan University of Medical Sciences. 2012;11(1):85-92.

17. Technologists AoS. Surgical Technology for the Surgical Technologist: A Positive Care Approach. Nelson Education; 2012.

18. Tavakkol R, Eslami J, Zarshenas L, Amiri A. Evaluation of the Prevalence of Low Back Pain and its Relationship with Awareness about Predisposing Factors in Operating Room Personnel of Hospitals Affiliated to Shiraz University of Medical Sciences 2019. Shiraz University of Medical Sciences; 2020. 